\title{
EL USO DE LA LECTURA Y LA ESCRITURA COMO ESTRATEGIA PARA ENSEÑAR LA HIGIENE EN LA ESCUELA COLOMBIANA DE LOS ALBORES DEL SIGLO XX
}

\author{
Doris Lilia Torres Cruz ${ }^{\mathbf{1}}$ \\ Universidad Pedagógica y Tecnológica de Colombia \\ Grupo de Investigación HISULA \\ dorislilia6@yahoo.com \\ Tulio Alfonso Ramírez ${ }^{2}$ \\ Universidad Central de Venezuela \\ tuliorc1@gmail.com
}

Recepción: 18/04/2010

Evaluación: 15/06/2010

Aceptación: 12/11/2010

Artículo de Reflexión

\section{RESUMEN}

El objeto de este trabajo es resaltar el impacto que tuvo el pensamiento higienista en la escuela colombiana a comienzos del siglo XX en la enseñanza de la lectura y escritura. La investigación es de tipo documental, la cual se soporta en la búsqueda de fuentes primarias en los archivos del Ministerio de Educación Nacional, la Biblioteca Nacional de Colombia, el Fondo Pedagógico y Fondo Posada de la Universidad Pedagógica y Tecnológica de Colombia; las Memorias del Ministerio de Instrucción Pública de 1903-1930, junto con el Diario Oficial, ubicado en el Archivo del Departamento

\footnotetext{
1 Licenciada en Idiomas Modernos, Magister en Lingüística y Doctora en Ciencias de la Educación - RUDECOLOMBIA, integrante del grupo de investigación Historia y Prospectiva de la Universidad Latinoamericana HISULA y Lenguajes en Educación Leen. 2 Coordinador del Doctorado en Educación. Sociólogo de la Universidad central de Venezuela. Abogado. Universidad central de Venezuela. Magister en relaciones industriales. Mención formación de recursos humanos universidad católica Andrés Bello. Doctor en filosofía y ciencias de la educación. Universidad nacional de educación a distancia (uned), Madrid, España. Profesor Titular de la Escuela de Educación de la Universidad Central de Venezuela. Pregrado y Postgrado .Profesor Titular del Instituto Pedagógico de CaracasUPEL. Pregrado y Postgrado.
} 
de Boyacá. Este documento ofrece la posibilidad de reconocer la incidencia de los factores externos a la enseñanza de la Lectura y escritura, como elementos significativos en el desarrollos del proceso lector escritural que tuvo Colombia a comienzos del siglo XX. Si bien la lectura y escritura se promovió con fines utilitaristas y prácticos, que aportaron al manejo de la técnica, la industria fabril y la agricultura; también estuvo al servicio del pensamiento higienista que promovió la limpieza y el esplendor de la lengua. El identificar la lectura y escritura como instrumentos ajenos a la condición misma del sujeto, genera la imposibilidad de incrementar procesos críticos, con sentido y participación dentro de un proceso de construcción de nación.

Palabras clave: Escuela, Lectura, Escritura, Higienismo.

\title{
THE USE OF THE READING AND THE WRITING LIKE STRATEGY TO TEACH THE HYGIENE IN THE COLOMBIAN SCHOOLAT THE BEGINNING OF THE 20TH CENTURY
}

\author{
Doris Lilia Torres Cruz ${ }^{\mathbf{1}}$ \\ Universidad Pedagógica y Tecnológica de Colombia \\ Grupo de Investigación HISULA \\ dorislilia6@yahoo.com \\ Tulio Alfonso Ramírez ${ }^{2}$ \\ Universidad Central de Venezuela \\ tuliorc1@gmail.com
}

\begin{abstract}
The purpose of this paper is to shown the impact it had thought hygienist school in Colombia in the early twentieth century in the teaching of reading and writing. The research is documentary, which is supported in the search for primary sources in the archives of the Ministry of National Education, the National Library of Colombia, the Fund and Fund Teaching in Pedagogical and Technological University of Colombia, the Memoirs of Ministry of Education in 1903-1930, the Official Gazette, located in the Archives of the Department of Boyacá. This document offers the possibility of recognizing the impact of external factors on the teaching of reading and writing, as significant elements in the development of reading process that took Colombia to the
\end{abstract}


Doris Lilia Torres - Tulio Alfonso Ramírez.

early twentieth century. While literacy was promoted utilitarian and practical purposes, which contributed to the management of technology, manufacturing industry and agriculture, also was in the service of thought that promoted hygienist and splendor of the language. Identifying reading and writing as tools other than the condition of the subject itself, generates the impossibility of raising critical processes, and meaningful participation in a process of nation building.

Key words: School, Reading, Writing, Hygiene

\section{INTRODUCCIÓN}

En el ámbito de la escuela primaria a finales del siglo XIX y comienzos del $\mathrm{XX}$, Colombia vivió los problemas pedagógicos de enseñar a leer y escribir bajo condiciones de precariedad económica y social, unidos a la preocupación que surgía por los problemas higiénicos y de salubridad pública en las clases menos favorecidas. En este sentido, se hizo mucho énfasis en la enseñanza de la lengua por fomentar la escritura y lectura desde la higiene corporal. Niños de condiciones sociales y económicas mínimas, que bien podían pertenecer a una región rural o a una comunidad indígena eran el punto de referencia, y de acuerdo con los preceptos legales, para catequizar y adelantar las respectivas Misiones Católicas; éstos fueron los encargados de salvar e instruir a los salvaje en la fe por medio de la lectura y escritura. Se partió de la necesidad de cambiar las costumbres sociales y culturales, que de una u otra manera originaban la alteración de la salubridad pública. La búsqueda por promover costumbres higiénicas básicas llevó a implementar la limpieza y el esplendor, la cual pasó desde las estructuras corporales hasta la implementación de brigadas y comités de salubridad escolar tanto a nivel local como nacional.

La Junta de Salubridad Pública a nivel nacional hacía un llamado al gobierno central para que ayudara a los centros de Instrucción, dado que en su mayoría fueron tomados por el ejército nacional y convertidos en cuarteles; con lo cual, habían dejado a las instalaciones escolares en condiciones higiénicas lamentables.

Convertidos en cuarteles los locales de las escuelas durante la última revolución, sufrieron tan terrible deterioro que hasta hoy no han podido conseguir su completa refección, a pesar de los muy laudables esfuerzos tanto del gobierno departamental como de las Municipalidades. Muy justo habría sido que la Nación hubiera prestado con este objeto algún auxilio 
a los Municipios, toda vez que el deterioro de sus locales fue causado por fuerza del Ejército Nacional. ${ }^{3}$

La Guerra de los Mil Días, había permitido que los batallones ocuparan las instalaciones escolares, las mismas que, posteriormente, fueron usadas como cuarteles encargados de los trabajos del Ferrocarril de Girardot. Las instalaciones escolares, utilizadas como cuarteles durante la guerra, quedaron en ruinas. Esto hizo imposible que las escuelas continuaran funcionando en ellas. Por esta razón, y para evitar una suspensión de tareas escolares, tuvo a bien el Gobierno, autorizar a los Inspectores celebrar contratos de arrendamiento de locales ah doc para ser utilizados como escuelas, mientras que con el presupuesto de Instrucción pública se hacían las reparaciones necesarias.

Así mismo, la carencia de útiles de enseñanza era absoluta en todo el país. Muchas escuelas tuvieron que suplir la falta de tiza con tierra blanca o cal; pero la falta de pizarra y gises, y la de papel y plumas, no era posible suplirla con nada. Tampoco había textos de lectura, con lo cual se decía que si bien el conocimiento de las primeras letras podía el maestro enseñarlo de cualquier manera, la lectura mecánica y la ideológica requerían de un texto uniforme y suficiente para el número de alumnos. La falta de insumos aunado al deterioro de la infraestructura escolar llevó en buena medida al incremento de enfermedades escolares y a la búsqueda constante por implementar, promover y asegurar las condiciones higiénicas de los escolares.

En todo el país los informes de los Inspectores hacían referencia a las circunstancias lamentables en las cuales funcionaban las escuelas. Así el Vicario apostólico de Casanare manifestaba: "Yo me estoy sacrificando con el simulacro de escuela que tengo. La abrí el 11 del corriente a pesar de todas estas dificultades, instalándola en una de las piezas de la casa que habíamos desocupado (la misión) porque estaba y está desplomada."4

La queja general tenía que ver con las condiciones de pobreza en la cual estos crecían, de tal manera que la escuela los recibía con las manos en los bolsillos, sin nada más. Así mismo, las condiciones físicas y de higiene dejaban

3 REVISTA DE LA INSTRUCCIÓN PÚBLICA DE COLOMBIA. Periódico Oficial destinado al fomento y a la estadística de los establecimientos de la enseñanza pública. Informe de Director de Instrucción Pública del Departamento de Cundinamarca. Bogotá: Imprenta Nacional, Julio 31 de 1905. Número 1, p. 59.

4 INFORME DEL VICARIO APOSTÓLICODE CASANARE. Inspector de Instrucción Pública en las Escuelas de Este territorio de la Intendencia del Meta, en el semestre I, del año de 1905. 
mucho que lamentar. A esto se agregaba la condición climática como un elemento que influía significativamente en el desarrollo de los niños. El deseo era repoblar estas regiones y hacer saneamiento de estas poblaciones tropicales, donde la raza blanca no podía acceder fácilmente, lo que llevaba a un atraso continuo y permanente. No era gratuito que el Ministerio de Instrucción y Salubridad pública estuvieran fusionados; eran las escuelas el recinto sagrado que debía promover el saneamiento y el mejoramiento de estos pueblos. Así se encontraba en las publicaciones que el Ministerio emanaba a todo el territorio.

El problema de repoblar a estas regiones... estriba case exclusivamente en su saneamiento. Desaparezca la realidad o la obsesión de la fiebre amarilla, y acudirán del interior familias blancas, artesanos, peones, pequeños comerciantes e industriales, que serán elementos estables de población, promovedores de verdaderos intereses, afectos y riquezas nacionales. (...) si como en otras regiones tan cálidas como las de esta comarca, hasta el europeo blanco ha logrado aclimatarse y arraigar definitivamente con los recursos de la higiene... porque no habrán acomodarse los peones de nuestra altiplanicie. Y no lo consiguen por los inveterados hábitos antihigiénicos. $^{5}$

Si bien las condiciones tanto físicas, sociales y culturales a comienzos del siglo XX se veían como deplorables, no eran inferior a las circunstancias que rodearon al país en torno a los debates para el mejoramiento de estos territorios, los cuales se caracterizaban por las aglomeraciones de barracas, casas de madera ubicadas desordenadamente, chinchorros o casas de vecindad, en los cuales no podían vivir los artesanos blancos que quisieran poblar estas regiones; vivía hacinados seres de todas las razas, confundidos entre sus miserias y sus desaseos en cuartuchos sin ventilación ni luz, donde en reducido espacio pernoctaban en repugnante promiscuidad; teniendo allí que satisfacer todas sus necesidades y quehaceres domésticos. El tufo de la estufa se mezclaba con los olores de las viejas latas de zinc y las cortinas de harapos que colgaban de los corredores. Un patio común de tierra o de arena cenagosa infectada les servía de desahogo y basurero, donde la mujer con sus crías se bamboleaba sobre la nata verdinegra de las aguas del lavado y en medio de una nube de mosquitos que incubaban los barriles y latas descubiertas, y envueltas en esa atmosfera hedionda que esparce el excusado excavado a pocos palmos de tierra, que el agua inunda, filtrando y resbalando las inmundicias. En medio de este festín de la fauna y flora tropical, solo podían resistir sus mortales asechanzas la raza negra. ${ }^{6}$

5 REVISTA DE LA INSTRUCCIÓN PÚBLICA DE COLOMBIA. Las mejoras sanitarias. Tomo XVIII. Número 2. Bogotá - Agosto '1905, pp. 222-227

6 Ibídem., p. 223. 


\section{Raza y escuela}

A medida que avanzó el tiempo, estas preocupaciones sobre la higiene y la salubridad pública afloraron en debates alrededor de la raza y la apología al mestizaje. El Médico Boyacense Miguel Jiménez López ${ }^{7}$ propició el debate sobre la degeneración de la raza. Manifestaba siguiendo a Benedict Agustin More, ${ }^{8}$ que la degeneración física, intelectual y moral de la especie humana eran el resultado de la conducta inmoral de los pueblos. Afirmaba que la enfermedad mental surgía por la herencia de factores físicos, de transgresiones morales y por la "Ley de la progresividad", que sugiere que cuando aparece un trastorno nervioso en una familia, la estirpe camina hacia la decadencia. Argumentaba que los primeros descendientes padecerán neurosis; los segundos, psicosis; los terceros debilidad mental y con ellos el linaje se agotaba ${ }^{9}$.

En concepto de López, los aborígenes eran de razas deficientes, dadas sus malas costumbres alimenticia, y especialmente por la embriaguez con la chich $a^{10}$. Estos se sometían, disminuían y reducían su capacidad de pensar al extremo ${ }^{11}$. Como mestizos representábamos la locura en forma de aberraciones, degeneraciones, neurosis y baja capacidad cerebral ${ }^{12}$. Afirmaba que las causas

\footnotetext{
7 Miguel Jiménez López. Edición original: 2004-12-01.Publicado: Biblioteca Virtual del Banco de la República Creador: Biblioteca Virtual del Banco de la República. Miguel Jiménez López nació en Paipa, departamento de Boyacá, el 24 de Julio de 1875, cursó estudios secundarios en el Colegio de Boyacá y en el Seminario de Tunja, ingresó a la Facultad de Medicina de la Universidad Nacional de Colombia en donde, en 1899, optó al título respectivo con la tesis: "Estudio Médico-Sicológico de la Interdicción Judicial por Causa de Locura". Participó en la guerra civil de 1895 en la que fue herido, y en la guerra de los Mil Días como médico jefe de las ambulancias de los ejércitos del gobierno, cargo en el que también asistió a la batalla de Palonegro. Terminada la contienda ejerció su profesión en Boyacá, y de 1908 a 1912 residió en París en donde frecuentó los servicios psiquiátricos y asistió a las disertaciones de notables maestros.

Fue Ministro de Gobierno en 1922, representante a la Cámara, Senador de la República, Presidente del Directorio Nacional Conservador y miembro de la comisión que redactó en 1932 la Plataforma Política de esa colectividad; fue representante de Colombia con carácter de Embajador ante la Asamblea de las Naciones Unidas en 1951. En 1943 asumió la cátedra de Psiquiatría en la Pontificia Universidad Javeriana, y en ese mismo año, fue nombrado director del Manicomio de Varones de Sibaté, cargo que desempeñó hasta 1947. Como siquiatra forense participó en sondados casos como los del Conde de Cuchicute, el proceso Zawadzki y el debate realizado en la Academia Nacional de Medicina sobre la personalidad del Libertador. Falleció en Bogotá el 22 de Agosto de 1955.

8 un hombre profundamente religioso y muy influyente en la psiquiatría francesa. En 1857, publicó su "Tratado de la degeneración física, intelectual y moral de la especie humana".

9 JIMÉNEZ, M. "La locura en Colombia y sus causas" en: Revista Cultura. Vol. 3, Nro. 16, pp. 216-233

${ }^{10}$ Bebida alcohólica, elaborada a base de maíz, panela (dulce) y especias. Originaria de los pueblos indígenas.

${ }^{11}$ Ibídem., p. 216 ss

12 Ibídem., p. 220 ss.
} 
Doris Lilia Torres - Tulio Alfonso Ramírez.

eran el consumo de chicha, el uso de las aguas naturales, el consumo de carnes de animales en descomposición (carnes nitradas, asadas con el sol, oreadas), el clima y la sífilis. La educación era lamentable, descuidaba el desarrollo de la voluntad, desperdiciaba las energías del individuo, con los métodos para enseñar a leer y escribir deformaba físicamente el cuerpo y lo sometía a toda clase de epidemias. El resultado de estos métodos educativos que olvidaban la voluntad y el cuerpo se resumían en la fatiga intelectual y moral de los niños del país. ${ }^{13}$

En diferentes escenarios, ${ }^{14}$ Jiménez López intentó dar prueba que corroboraran el decaimiento de las raza mestiza, junto con las secuelas que dejaba. Reunió estadísticas de enfermedad mental y suicidio, mostro ejemplos de deformación física y enumeró todas las posibles enfermedades contagiosas que reproducían vertiginosamente ${ }^{15}$. Por lo tanto, creer que esta raza podía tener niveles intelectuales superiores era perder el tiempo; de tal manera que no era sorprendente que en la escuela se observaran niños con dificultades para leer y escribir, con deformaciones físicas, emocionales y con condiciones de precariedad en todos los sentidos. Por lo tanto, el país no podía esperar tener ningún tipo de contribución a la ciencia mundial, ni personas cultas y letradas con unos niveles intelectuales superiores a los actuales y muy distantes de los alemanes. Las escuelas estaban saturadas de estudiantes débiles, e inapetentes de conocimientos. En definitiva, los niños pertenecían a una degradación de la raza y por lo tanto, las escuelas primarias saturadas de las clases analfabetas y menos favorecidas mentalmente para el aprendizaje, debería promover las condiciones tanto físicas como sociales para limpiar de todas esas malas costumbres y actitudes generadas por la sociedad. Era necesaria una buena nutrición, implantar «obligatoriamente » el aseo corporal, reglamentar el trabajo y del descanso, revisar la propuesta educativa para "dar a la cultura física toda su importancia desde la primera edad", y promover modales acordes con un espíritu culto.

Por lo tanto, López propuso la adopción de políticas de inmigración: la importación de una raza cuyo número y características permitan ahogar progresivamente nuestros rasgos de degeneración. La describe de manera taxativa:

Raza blanca, talla y peso un poco superiores al término medio entre nosotros; dolicocéfalo; de proporciones corporales armónicas; que en él domine un ángulo facial de $82^{\circ}$ aproximadamente; de facciones proporcionadas para

\footnotetext{
13 Ibídem., p. 228 ss.

${ }^{14}$ El Tercer Congreso Médico Colombiano se reunió en Cartagena en enero de 1918.

15 JIMÉNEZ, M. (1920): Nuestras razas decaen. Algunos signos de degeneración colectiva en Colombia y en los países similares. El deber actual de la ciencia. Bogotá, Imprenta y litografía de Juan Casis, p. 234.
}

Rev. hist. edu. latinoam. Vol. 15. Año 2010, pp. 271 - 298 
neutralizar nuestras tendencias al prognatismo y al excesivo desarrollo de los huesos malares; temperamento sanguíneo nervioso, que es especialmente apto para habitar las alturas y las localidades tórridas; de reconocidas dotes prácticas; metódico para las diferentes actividades; apto en trabajos manuales; de un gran desarrollo en su poder voluntario; poco emotivo; poco refinado; de viejos hábitos de trabajo; templado en sus arranques, por una larga disciplina de gobierno y de moral; raza que en el hogar y la institución de la familia conserven una organización sólida y respetada; apta y fuerte para la agricultura; sobria, económica y sufrida y constante en sus empresas. ${ }^{16}$

La apariencia sólidamente científica de esta argumentación y la importancia intelectual de su ponente provocaron consecuencias. La Asamblea de Estudiantes de Bogotá, preocupada, organizó y financió una discusión pública sobre el tema. Las nueve conferencias se desarrollaron durante varios días a partir del 21 de mayo de 1920, en el teatro Municipal. A ella fueron invitados intelectuales ilustres de Bogotá y de Medellín: Luis López de Mesa (psiquiatra), Calixto Torres Umaña (fisiólogo), Jorge Bejarano (higienista), Simón Araujo (institutor), Lucas Caballero (sociólogo) y Miguel Jiménez López, quien la inauguró y la clausuró. En esas dos conferencias repitió y amplió las explicaciones y las propuestas ya planteadas. ${ }^{17}$

En educación propuso la enseñanza práctica en vez de la teórica ${ }^{18}$, exalto la condición obligatoria de la educación, la financiación estatal, la organización nacional, la continuidad de los métodos desde la primaria hasta la formación técnica y/o universitaria, la eliminación del examen oral único y su sustitución por múltiples pruebas escritas, la elevación académica de los maestros y el liderato de los filósofos y de los psicólogos del desarrollo (Kerschensteiner en Alemania, Buysse en Bélgica, Stanley Hall, Dewey y James en los EU $)^{19}$. Sus apreciaciones sobre este último aspecto revelan su participación en la inquietud e interés que generaban entre los psiquiatras las noticias sobre el desarrollo de

\footnotetext{
16 Ibídem., p. 30

${ }^{17}$ RINCÓN, Carlos. (2007): Seminario Universidad y nación. Doctorado en Ciencias de la Educación- RUDECOLOMBIA. Tunja, Boyacá, Colombia. Cátedra de 13 de Noviembre de 2007.

${ }^{18}$ Electronic Document Format (ISO).TORRES GUTIERREZ, MANUEL. UN PSIQUIATRA DECIMONÓNICO EN EL SIGLO XX MIGUEL JIMENEZ LÓPEZ (1875 -1955). rev. colomb.psiquiatr. [online]. 2001, vol.30, n.2 [cited 2010-02-16], pp. 113140. Available from: http://www.scielo.org.co/scielo.php?script=sci_arttext\&pid=S0034$74502001000200002 \& \operatorname{lng}=e n \& n r m=i s o>$. ISSN 0034-7450.

${ }^{19}$ Ibídem., p. 2.
} 
las Escalas de Inteligencia por parte de Binet y Simón ${ }^{20}$ para predecir la evolución de los niños en el sistema educativo francés.

Al tiempo que en Colombia se daban estos debates eugenésicos, en Cuba Fernando Ortiz ${ }^{21}$ planteaba que su población era un ajiaco. José Vasconcelos ${ }^{22}$ hablaba de la raza cósmica, diciendo que la decadencia es la pérdida de la visión cósmica y la creación de una raza iberoamericana. La raza cósmica es más humana que la sajona. Spengler, ${ }^{23}$ a su vez, escribe su ensayo Decadencia de occidente. Donde plasma los procesos de acuerdo con la naturaleza de las civilizaciones las cuales estaban relacionadas con los ritmos sociales y culturales del desarrollo humano. Se relaciona con el pensamiento de Vasconcelos en la medida que la pérdida es la falta de visión cósmica.

El mundo occidental se movía alrededor del tema de la raza y por lo tanto la educación era un instrumento que se podía utilizar para el mejoramiento de la

\footnotetext{
20 THÉODORE, Simón, (Dijon, 10 de julio 1872 - París, 1961) fue un médico psiquiatra, y psicólogo francés. Estudió Medicina y se doctoró en Psiquiatría. Aunque colaboró con los médicos de alienados más reputados de su época y a pesar de haber publicado varios artículos en colaboración con Binet, su fama dentro del mundo psicológico y pedagógico le ha venido dada por haber elaborado, junto con Binet, una Escala para medir la Inteligencia. Sus escasos biógrafos destacan de él su humildad por encima de todo, pues pudiendo haberse aprovechado de la fama que podría haber alcanzado al haberse muerto prematuramente su maestro, siempre hizo mención expresa de que el auténtico creador de la famosa escala era Binet y él un simple colaborador suyo. Al decir de algún biógrafo, parece que publicó alguna obra literaria destinada a los niños.

${ }^{21}$ ORTIZ, Fernando, las Razas y los Negros. GODOY, Gustavo J. (1966): Journal of InterAmerican Studies, Vol. 8, No. 2, pp. 236-244.Published by: Center for Latin American Studies at the University of Miami .Stable URL: http://www.jstor.org/stable/165106

22 VASCONCELOS, José. (1926): La raza cósmica. Misión de la raza iberoamericana. Notas de viaje a la América del Sur. Barcelona, Agencia Mundial de Librería, p. 56.

${ }^{23}$ En su ensayo La decadencia de Occidente ( $1^{\text {er }}$ volumen 1918 y $2^{\circ}$ volumen 1923 ) alega que el desarrollo de las civilizaciones sigue un modelo cíclico reconocible según tres tipos de sociedad que se irían sucediendo en el tiempo hasta llegar a una cuarta final de decadencia: la Apolínea o Clásica; la Mágica, propia del mundo islámico, la Fáustica u Occidental, y la de Decadencia. Cada una de estas sociedades tendría un nacimiento, una madurez y una vejez que podía implicar su desaparición. Spengler, gran experto en la filosofía de Heráclito, basa su idea del isomorfismo en los estudios naturalistas de Goethe. A partir de ellos concibe un orden natural intrínseco a cualquier sistema dado, orden que debe cumplir obligatoriamente a lo largo de su desarrollo y manifestación. Como este orden o forma es generalizable a todos los niveles de la realidad, la cumplen desde las plantas en su crecimiento hasta las civilizaciones, pasando por el Cosmos mismo. Es así como acuña el concepto de "isomorfismo" aplicado al ámbito de la realidad social y la Historia. Como conclusión a su estudio de Heráclito, Spengler sostiene que la vida humana y la historia de la humanidad son una lucha constante entre la fijicidad y la movilidad, entre estados y procesos. Spengler, pese a lo poco citado que resulta en los círculos académicos, es una influencia constante en el siglo XX. Entre otros, determinó los escritos de Georg Henrik von Wright sobre nuestra sociedad. También fue influencia nodal en Francis Parker Yockey, quien escribió Imperium a modo de secuela de La decadencia de Occidente. Yockey llamó a Spengler "El filósofo del siglo XX".
} 
misma. La educación debería buscar el blanqueamiento de la raza, con el fin de alcanzar el desarrollo de los pueblos. La enseñanza de la lectura y escritura no quedó por fuera de esta polémica, y si bien se quería establecer un canon, que mejor que plasmar grabados imágenes de Santos y laicos con rasgos europeos que dejaran clara la superioridad de estas culturas y de estas razas.

La tres primera décadas del siglo XX, las cerro Laureano Gómez, periodista y político conservador, quien dio, en junio de 1928, una conferencia pública en el Teatro Colón de Bogotá en la que describió un vuelo aéreo sobre la costa Caribe de Colombia. La geografía tropical de la zona le recordaba a la cuenca del río Amazonas con su exuberante verde, su paisaje virgen y, para su preocupación, el estado incivilizado en que vivían las poblaciones que lo habitaban. Este último elemento resultó ser el centro de la crítica de Gómez a la sociedad colombiana, especialmente a la parte que vivía en las márgenes físicas y sociales, alejada de la vida cultural de las provincias del interior.

Esta metafísica primitiva [de las tribus amazónicas] tiene una consecuencia forzada que podemos observar entre nosotros, en algunas comarcas del Bajo Magdalena y de los otros ríos tropicales...Es una profunda inercia para la cultura, una letargia invencible. El medio ambiente era en parte responsable de ese letargo: "bajo aquel suntuoso y aterciopelado manto no hay nada útil para la vida humana, sino bejucos y maleza. ${ }^{24}$

Sin embargo, el problema también estaba en el hecho que, según Gómez, la Costa había caído bajo el influjo de una cultura extranjera, en particular la norteamericana. Peor aún, la región del Caribe se había formado por "el espíritu del negro, rudimentario e informe, como que permanece en una perpetua infantilidad." Además de ser mentirosos y adoradores de falsas imágenes, los negros pertenecían a las "raza[s] salvaje[s]" que constituían "los elementos bárbaros de nuestra civilización”. Al final de su juicio negativo sobre la región Caribe, Gómez afirmó que "en largos trayectos de vuelo, no se distingue huella alguna de vida civilizada." 25

El tema de la eugenesia y su relación con el poco progreso que mostraba el país no se alejo de las aulas y las practicas de lectura y escritura de la realidad escolar. Algunos líderes y políticos del momento acogieron la instrucción pública como un medio para alcanzar el propósito del mejoramiento y el progreso del

\footnotetext{
${ }^{24}$ Conferencia de 1928

${ }^{25}$ MCGRAW, Jason. (2007): Purificar la nación: eugenesia, higiene y renovación moral-racial de la periferia del Caribe colombiano, 1900-1930. rev.estud.soc. [online]. n.27, pp. $62-75$.
} 
país. A falta de capacidad institucional para gobernar el país estas teorías fueron un buen escudo sobre el cual se protegieron muchos políticos y líderes sociales que quisieron hacer protagonismo y determinar las causas del atraso social. El lenguaje de moralidad reinaba por todas partes y reforzaba la idea de la diferencia social en los programas de educación e higiene, con un afán desmedido limpiar y dar esplendor a nuestro país. Se promovió la purificación moral y la salud espiritual en todos y cada uno de los establecimientos escolares. Para fortuna de algunos inspectores de instrucción pública, los misioneros llevaban medicinas y sobre todo la palabra Dios, con el fin de ofrecer salud del alma y del cuerpo a los pobres moradores de las regiones habitadas del país. Estas razas degradadas necesitaban inyecciones de de buena raza blanca ${ }^{26}$. Bajo esta condiciones el Congreso de la República no dudo en aprobar rápidamente la Ley 12 de 1926, la cual fue propuesta Antonio José Uribe, y quien fuera otrora el promotor de la Ley Orgánica de Educación 39 de 1903; la Ley 12 de $1926^{27}$ estableció que el Ministerio de Instrucción y Salubridad Públicas, de acuerdo con la Dirección Nacional de Higiene, debía formar y publicar los programas detallados y los horarios, así como instrucciones especiales para los maestros de enseñanza, teniendo en cuenta las condiciones y necesidades peculiares del país. Dada la suprema necesidad y utilidad públicas del saneamiento de los puertos marítimos de Buenaventura, Tumaco, Cartagena, Puerto Colombia, Santa Marta, Riohacha y Tolú, los puertos fluviales de Barranquilla, Puerto Wilches, Puerto Berrío y la Dorada, de Barbacoas, de Quibdo y de Guapí, y los terrestres de Ipiales y Cúcuta.

El Ejecutivo, de acuerdo con la Dirección Nacional de Higiene y oídos el dictamen de los Gobernadores y de los Concejos Municipales respectivos, debía proceder a contratar las obras que fueran necesarias para el saneamiento de los puertos citados, empezando por la dotación de un abundante servicio de aguas, de alcantarillado y de pavimentación. El Gobierno, de acuerdo con el Director Nacional de Higiene y con los Gobernadores de los Departamentos, presentaba un plan para sanear, en el menor tiempo posible, las principales ciudades de la República, especialmente dotándolas de aguas potables abundantes, alcantarillado, canalización y pavimentación adecuada y saneamiento de las habitaciones. Con este fin se autorizaba al Poder Ejecutivo para contratar en el Extranjero, por cuenta de la Nación, una comisión técnica que formara los planos de las obras que debían ejecutarse, las cuales serian costeadas por los Departamentos y por los respectivos Municipios.

\footnotetext{
${ }^{26}$ Ibídem., p. 70.

${ }^{27}$ Diario oficial 20307 lunes 27 de septiembre de 1926.Ley 1926 0012. (Septiembre 25). "Sobre enseñanza de la higiene, saneamiento de los puertos marítimos, fluviales y terrestres y de las principales ciudades de la República".
} 


\section{La salud de los escolares en sus diversas manifestaciones}

Las Juntas Centrales de Higiene emitían acuerdos ${ }^{28}$ con el fin de establecer las obligaciones higiénicas de los maestros de las escuelas. Así ningún Director de escuela podía permitir que un alumno se matriculara sin que presentara un certificado del vacunador oficial o de un médico titulado, en donde constara que había sido vacunado y revacunado oportunamente.

El jefe de la oficina de Vacunación de Bogotá debía visitar los establecimientos de educación públicos y privados de la capital, a fin de determinar si habían alumnos que no estuvieran vacunados, y de vacunarlos y revacunarlos si los hubiere en este caso. Estas visitas deberían practicarse en todos los establecimientos de educación en el curso de los cuatro primeros meses del año. El certificado expedido lo remitía el Director de la escuela a los médicos de la oficina de sanidad del Distrito Capital con la lista de todos los alumnos.

A sí mismo, las Juntas Departamentales de Higiene dictaban las disposiciones que estimaban necesarias de acuerdo con las condiciones ambientales, además de solicitar ante el Ministerio de Instrucción y Salubridad Pública el cow-pox que necesitaban para la vacunación de escuelas y colegios del país. ${ }^{29}$

\section{Higiene de las escuelas}

El tema de la higiene se constituyó en uno de los temas centrales de las secciones científicas publicadas por el Ministerio de Instrucción y Salubridad Pública. Los templos del saber, como se denominaron las escuelas, estaban llamados a cumplir a cabalidad su misión de limpiar, tanto en cuerpo como en alma, a esto seres "pecadores e impuros" en todos los sentidos.

Consecuentes con estas políticas educativas se promovió la gimnasia sueca y que de acuerdo con los higienistas, llevaba a desarrollar las demás facultades del alumno. Se dirimía la polémica en relación con el género y se establecía tanto para niñas como niños. De igual modo, se planteaba la inquietud que si Europa se quejaba de tener niños en las escuelas encorvados, descoloridos bajo la ley de un trabajo prematuro e intenso, que podríamos decir de nuestras escuelas

\footnotetext{
${ }^{28}$ REVISTA DE LA INSTRUCCIÓN PÚBLICA DE COLOMBIA (1905). Juntas Centrales

de Higiene. Tomo XVII- Julio a Diciembre. Bogotá, Imprenta Nacional., p.567.

${ }^{29}$ ACUERDO NÚMERO 6 DE 18 DICIEMBRE DE 1905.
} 
antihigiénicas, en las que ni siquiera se hacía mención de la educación física del niño. Se promovía como ejemplo a seguir la Academia Real de Stockolmo, la cual utilizaba ejercicios metódicos y se sugería el manual de Schreiber, el cual era apoyado por pedagogos inteligentes como Pestalozzi y Ling. ${ }^{30}$

De igual manera, constantemente se pusieron como ideal la escuela alemana y suiza, donde se imponían los ejercicios gimnásticos; por lo tanto, mucho más los niños de aquí, que estaban sometidos a condiciones climáticas e higiénicas adversas.

Si los ejercicios gimnásticos se imponían en todas partes, en nuestro país los consideramos ineludibles; es el único medio de dar al organismo el grado de resistencia necesario para que la acción del clima, tan debilitante de por sí, no actúe libremente, destruyendo sin oposición ni tregua la raza y preparando su degeneración. ${ }^{31}$

Así, se proclamaba que la escuela fuera muy general en conocimientos, pero fuerte y robusta en el entrenamiento físico de los niños. Que varías enfermedades podían contraerse en la escuela por las condiciones antihigiénicas que presentaban: la miopía, la cual se evitaba con un buen mobiliario y el dar a la enseñanza oral una proporción mayor que la escrita ${ }^{32}$; cefalalgia escolar, se daba por mantener los niños mucho tiempo sentados; escrófula escolar, dada por las condiciones climatológicas; dispepsia, cuando los niños trabajan durante la digestión; desviaciones vertebrales, por malas posiciones durante la escritura; a las niñas se les recomendaba que se sentaran casi pandeadas, lo cual les generaba una posición falsa de la columna llamada ensilladura. La posición natural era la más favorable de todas.

Finalmente, se esperaba que la casa de enseñanza no fuera por sus condiciones antihigiénicas, por falta de aire, por aire viciado o por exceso de trabajo intelectual y falta de trabajo físico, una causa más que predispusiera a los niños a estas dolencias.

\section{Higiene de la inteligencia}

Se esperaba que las horas de clase del alumno fueran agradables, no las inspirara el temor, ni se convirtieran en un suplicio; este era el ideal que debía

\footnotetext{
${ }^{30}$ REVISTA DE LA INSTRUCCIÓN PÚBLICA DE COLOMBIA (1893). Sección Científica. La Higiene de las escuelas. Tomo I. Bogotá: Tipografía de la luz., p. 313.

${ }^{31}$ Ibídem., p. 313.

32 Ibídem., p. 314.
} 
conseguirse. La repugnancia por la escuela era hija de la falta de método ${ }^{33}$, la poca estimulación de la curiosidad innata del niño por conocer aquello que le rodeaba y lo que le interesaba. Se reclamaba que el método utilizado por la mayoría de los profesores era muy deficiente, dado que al maestro se le exigía demasiado trabajo y no podía cumplir con sus deberes. Se criticaba el hecho de que un mismo profesor dictara todas las materias mientras que en los países norteamericanos, existía una para cada asignatura. La ayuda del monitor en muchos casos era deficiente y rebajaba el prestigio de la profesión. Igual ocurría con los niños quienes en su mayoría no soportaban la librería que llevaban encima, sumadas al método memorístico que debían ejercer en cada una de ellas. ${ }^{34}$

Se sugería para la higiene de la inteligencia, graduar las lecciones de memoria por las lecciones entendidas, al acostumbrar al alumno a exponer su raciocinio y a razonar después que el profesor hubiera explicado la lección. Así mismo, se recomendaba dar preferencia al método oral más que el escrito. ${ }^{35}$

La higiene mental promovía el desarrollo de todas las facultades y no de unas sobre las otras, en este caso el de la memoria sobre las demás. Así un maestro debía reconocer las capacidades individuales de cada niño y entender que cada uno era diferente. Lo más importante era que el alumno disfrutara de las lecciones. Así mismo, se hacía una excepción en el caso de las mujeres, quienes venían al mundo con el sello del feminismo. El cual le daba una organización mental distinta, unida al legado de predisposiciones morbosas físicas y de predisposiciones morales e intelectuales, contra las cuales se esperaba que la educación se opusiera paulatinamente, para cambiarlas en lo que de nocivo tuvieran ${ }^{36}$. Se recomendaba cuidar el delicado sistema nervioso de la mujer del histerismo, el cual podía ser adquirido en la escuela o generar una predisposición hacia él, comprometiendo así la felicidad de la familia. En cuanto al hombre se sugería fortalecer la educación intelectual con la física, con el fin de moderar su emotividad, atenuar las exigencias de una imaginación harto ligera y fomentarle por todos los medios la robustez física e intelectual, con el fin de que llegado el día, pudieran dar hijos fuertes para la patria, y dirigidos por sí mismos. ${ }^{37}$

La higiene de la inteligencia se asoció con la higiene física y promovió el desarrollo de las facultades con fines eminentemente reproductivos y de acuerdo con criterios morales y religiosos.

\footnotetext{
${ }^{33}$ VALLE ATILES, F. (1893): "La higiene de la inteligencia", en: Revista de la

Instrucción Pública de Colombia. Tomo I. Bogotá, Imprenta de la luz, p. 317 ss.

${ }^{34}$ Ibídem, p. 313

${ }^{35}$ Ibídem, p. 318

${ }^{36}$ Ibídem, p. 319

${ }^{37}$ Ibídem, p. 319
} 
Doris Lilia Torres - Tulio Alfonso Ramírez.

\section{Instrucciones de los Institutores a las familias de alumnos atacados por enfermedades epidémicas y contagiosas}

El Ministerio de Instrucción y Salubridad Pública por medio de la Revista, promovió los temas relacionados con el pensamiento higienista y adjunto los cuidados que de una u otra manera debían los maestros promover en cada uno de sus sitios de trabajo. ${ }^{38}$

Así cada maestro se vio obligado a transmitir esta información y llevarla a cabo al pie de la letra. Por ejemplo si un institutor advertía una enfermedad contagiosa, debía enviar al niño al médico, donde hubiera uno; o en caso contrario aislarlo para evitar que se propagara la enfermedad. Era importante que el maestro expresara a los niños que estas enfermedades no debían inspirar miedo en ninguna ocasión, puesto que con toda seguridad la comunidad y con las condiciones de higiene que se tuvieran, se podían evitar la propagación de los gérmenes. Se mostraba que estos bichos podían esconderse en todas partes, pero que los niños no podían verlos; por eso era muy importante mantener las condiciones de higiene de cada uno y de los hogares ${ }^{39}$. En los hogares, los niños debían permanecer en un cuarto aislado, el cual no debía contener absolutamente nada; únicamente la cama, la cual debía permanecer en el centro del cuarto; debía permanecer completamente aislado y solo en compañía de la persona que lo podía asistir. Los alimentos que no consumiera el paciente debían inmediatamente quemarse. Se recomendaba también, que era necesario dejar en el cuarto del paciente un recipiente con agua, en donde pudiera escupir, pues los esputos, al secarse, podían extender en el aire el contagio. El contenido se debía depositar en un hueco lejos de la casa y taparlo con suficiente tierra. Se les hacía énfasis a los niños de mantener un escrupulosísimo aseo en todos los aposentos de la casa y que se cuidaran de abrir las puertas y las ventanas diariamente y el mayor tiempo posible a fin de que el sol y el aire penetrara libremente en ellos. ${ }^{40}$

\footnotetext{
${ }^{38}$ REVISTA DE LA INSTRUCCIÓN PÚBLICA DE COLOMBIA. (1905): Enseñanza antialcólica. Bogotá, Imprenta Nacional, p. 51. Se reclamaba ante el Ministro de Instrucción Pública la necesidad de disponer del libro de lectura en las escuelas donde se hacía una cruzada contra el alcoholismo; y que siendo las escuelas el lugar más apropiado para la propagación de esta ideas, no se iban a escatimar esfuerzos por lograrlo. Así mismo se informaba acerca de la creación de sociedades de temperancia con el apoyo de cada uno de los maestros.

39 REVISTA DE LA INSTRUCCIÓN PÚBLICA DE COLOMBIA. (1896): Tomo V. Bogotá, imprenta de La Luz, calle 14, número 70, apartada aéreo 160, teléfono 40. Sección científica. Consulado de Colombia- St Nazaire (Loire - in fre) - Número $245-$ Junio 1 de 1896 , p. 257 ss.

${ }^{40}$ Ibídem, pp. 258-259.
} 
Lo anterior, se hacía posible cuando se contaba con las comodidades económicas aceptables, pero cabe recordar que las condiciones sociales de nuestro país a comienzos del siglo XX no fueron las mejores y que si bien se promovía el progreso, buena parte de éste quedó en el papel.

\section{Exclusión de la escuela}

Los maestros tenían la obligación de excluir a los niños de la escuela cuando presentaban la escarlatina, ${ }^{41}$ crup, ${ }^{42}$ viruela o sarampión. No podía el niño volver a la escuela antes de 40 días, contados desde el de la aparición de la enfermedad; ni antes de 16, en los de sarampión. Era deber del institutor el enviar los niños atacados de la enfermedad contagiosa a sus hogares, inmediatamente advirtieran que estuvieran contagiados. Era importante recalcarles a los padres tomar las medidas higiénicas necesarias y hacer que los vecinos las implantaran a su vez. Así mismo se debía proceder con todas las enfermedades epidémicas contagiosas comunes en Colombia a comienzos del siglo XX, como fueron: la cólera, el tifo, la fiebre tifoidea, las viruelas, el crup, ciertas anginas, la escarlatina, el sarampión, la fiebre diaforética o sudor ánglico (morbus sudatorius), la disentería epidémica y la tisis ${ }^{43}$.

\section{Higiene de la lectura y la escritura}

En una sinopsis razonada de los principios de moral y derecho, el Ministerio de Instrucción y Salubridad Pública ${ }^{44}$ promovía que el pensamiento libre, lo mismo que la libertad absoluta de leer o escucharlo todo, no es menos absurdo.

\footnotetext{
${ }^{41}$ Es una enfermedad trasmitida por contagio, generalmente por vía respiratoria, que se presenta con mayor frecuencia en niños en edad escolar de 2 a 10 años de edad (incluso hasta 12), pero raramente en adultos. A veces puede aparecer tras una faringitis estreptocócica y también puede aparecer tras otras enfermedades estreptocócicas como infección de una herida o sepsis puerperal. Un individuo puede tener varias veces la escarlatina debido a la formación de anticuerpos específicos contra las exotoxinas pirógenas. Los pacientes con inmunidad antibacteriana específica contra un tipo de estreptococo (con o sin inmunidad antitóxica), podrán no contraer la enfermedad al exponerse a ese tipo. Los pacientes sin inmunidad bacteriana específica (pero con inmunidad antitóxica) podrán contraer faringitis y los pacientes sin ninguno de los 2 tipos de inmunidad podrán contraer faringitis y escarlatina.El término crup no se refiere a una sola enfermedad, sino más bien a un conjunto de afecciones que cursan con inflamación de las vías respiratorias altas, la cual provoca una tos seca, similar al ladrido de un perro, particularmente durante el llanto.

${ }^{42}$ El término crup no se refiere a una sola enfermedad, sino más bien a un conjunto de afecciones que cursan con inflamación de las vías respiratorias altas, la cual provoca una tos seca, similar al ladrido de un perro, particularmente durante el llanto.

${ }^{43}$ REVISTA DE INSTRUCCIÓN PÚBLICA. Tomo V, óp., cit, p, 260.

${ }^{44}$ REVISTA DE LA INSTRUCCIÓN PÚBLICA DE COLOMBIA. Sección científica. Tomo I. Bogotá, Tipografía de la luz, p.443 ss.
} 
Doris Lilia Torres - Tulio Alfonso Ramírez.

Esta libertad engendraba el error del entendimiento como consecuencia natural. La experiencia les demostraba a los ideólogos de la educación que poner todos los libros en manos de los alumnos era incrementar la perturbación del orden y de la religión. Aquellos que lo hacían podían llamarse enemigos.

La lectura de las razones en pro y en contra de un hecho o una verdad dan por lo menos lugar a la duda en el común de los hombres, lo que es un grave mal para la inteligencia humana ${ }^{45}$.

Los promotores de leer todo sin restricciones de ninguna clase ocasionaban un grave mal para la inteligencia humana, por cuanto que los alumnos eran incapaces por sus condiciones personales para adquirir el conocimiento que derivaba de los libros. En su mayoría se podía decir que este conocimiento era estéril y no proporcionaba nunca ventajas equivalentes al peligro manifiesto encerrado en esas lecturas peligrosísimas. Así mismo se observaba que no había necesidad de tales lecturas, por cuanto los promotores de la verdad se hacían cargo en sus obras de las razones del adversario con la extensión que ellas pedían y según la calidad de los lectores para quienes escribían. Mas si la posición de la persona demandaba la lectura de obras en que se impugnaba la verdad, la autoridad encargada del bien de esas mismas personas no se opondrá al hecho, rodeándola a la vez de todas las precauciones indispensables para impedir el daño que podía temerse ${ }^{46}$.

\section{Higiene de la lectura}

La lectura tenía un origen eminentemente orgánico. Es decir surgía de la capacidad del ser humano de tener el sentido de la vista. Se partía del hecho de la ubicación de los ojos en la parte superior del cuerpo, lo que los llevaba a abarcar las más grandes distancias; puesto que parecían dos centinelas a la vanguardia para asegurar la convicción del mundo exterior, afianzar las relaciones con los seres cercanos, para mostrar a los hombres los goces a que está llamados a tomar parte y para salvaguardarlos de los peligros que los acechan ${ }^{47}$.

Desde una visión romántica era en ese doble donde se reflejaban los sentimientos más dulces, más ardientes, más amorosos, más excelsos que pudiera ofrecer la vida. Así si un artista representa el pudor lo hace con los ojos bajos. El poeta al inspirarse levanta los ojos hacia el cielo. El ojo crecía en la admiración

\footnotetext{
${ }^{45}$ Ibídem., p. 453.

${ }^{46}$ Ibídem., p. 454.

${ }^{47}$ REVISTA DE LA INSTRUCCIÓN PÚBLICA DE COLOMBIA. (1898). Tomo VIII.

Bogotá, Tipografía de la luz, p. 459.
}

Rev. hist. edu. latinoam. Vol. 15. Año 2010, pp. 271 - 298 
y permanecía fijo en el terror. Es decir, era un doble espejo que transmitía la imagen del hombre hacia el hombre.

Se invitaba a conservar e impedir la indiferencia con al que se trataba aun sentido tan precioso. De ahí que la ignorancia más absoluta del vulgo la consideraba como uno de los más simples elementos de la higiene ocular. Por lo tanto, se promovieron algunas reglas que debían seguirse para poder leer sin cansancio.

En primer lugar, los ojos podían moverse durante todo el día sin sentir el menor síntoma de fatiga, tanto en la escuela, el campo, la ciudad, contemplando el paisaje etc, Por lo tanto, se recomendaba que la visión de objetos lejanos y variados calmaba la vista. En caso contrario, cuando se trataba de observar objetos muy cercanos, unidos a la uniformidad en la monotonía de las líneas de la imprenta y en la lectura como tal, la vista se fijaba mucho, mientras que en otras actividades como el de la costurera, esta tenía la oportunidad de reposar, el escritor podía interrumpir su trabajo para reflexionar; el lector debía ver desfilar las palabras sin tregua ante su mirada constante, fija y estirada. ${ }^{48}$ Por lo tanto, no se debía leer con una asiduidad completa. Debía detenerse permanentemente para pensar que estaba leyendo y así contribuía a que los ojos descansaran. Era conveniente detenerse cada cuarto de hora o media hora para que los niños hicieran una reflexión sobre lo que leían.

Lo mismo se planteaba que otro elemento de cansancio de la retina era la proyección de imágenes accidentales. Quería decir esto que si se miraba con fijeza por cinco o seis segundo una faja blanca, trazada en medio de otras líneas negras y cerrar enseguida los ojos la lista blanca se veía como negra. Así, cuando se leía una página se reflejaba en la retina una serie de listas blancas y cenicientas. Así mismo, debía observarse que cuando se leía la mirada seguía con marcada precisión, la serie horizontal marcada por los caracteres de impresión y la línea recta trazada por la altura de la letra pequeña. Era entonces, por la altura de las letras superiores que se adivinaba la palabra. Por mucha dimensión que tuviera una palabra al cubrir la parte superior de ella no sería fácil adivinarla; por el contrario, acontecía que al cubrir la parte inferior, se podría leer con facilidad. ${ }^{49}$

Se mostraba como ejemplo los experimentos del Doctor Javal, ${ }^{50}$ quien comprobaba que desviando la mirada de un modo rigurosamente horizontal, se

\footnotetext{
${ }^{48}$ REVISTA DE LA INSTRUCCIÓN PÚBLICA DE COLOMBIA. (1898). Tomo VIII. 
afectaba las mismas partes de la retina por el blanco de las entrelíneas, mientras que las letras herían siempre las películas de estas membranas; de ahí la continua producción de imágenes accesorias. Se decía que si se tenía un libro en completa inmovilidad, y se sentía la impresión de una imagen casual, formada por bandas horizontales alternativamente claras y sombrías. Nada podía ser tan fatigoso para la vista como esas imágenes. Se mencionaba a Plateau, el célebre físico de Bruselas, quien había perdido completamente la vista por haber hecho un estudio demasiado profundo de la estabilidad de las impresiones retinosas, y que Newton sufrió, por la misma causa, por algunos días de ceguera completa.

Así se buscaba la manera de disminuir la intensidad de aquellas imágenes. Por medio de la posición que se toma al leer, pues al no tener el libro en inmovilidad, las bandas claras y oscuras no estarán constantemente colocadas en el mismo lugar de la retina. Fácilmente se desprendía de aquí el cansancio que producía la lectura en la cama. En general, cuando se leía en el lecho, se apoyaba el libro sobre el pecho y queda inmóvil, y según decía el doctor Javal, se hallaba la cabeza, por así la cabeza, por decir así, incrustada en la almohada. Esta ausencia de movimientos relativos del libro y de la cabeza, tendía a desarrollar la formación de las imágenes accidentales. A veces era de sorprenderse que después de un fuerte trabajo de diez o catorce horas diarias, no se canse la vista por la noche, al cabo de una lectura de dos horas. Sin embargo, nada de extraordinario había en eso.

Hay también que tenía en cuenta que se trabaja por la noche con luz artificial, la cual era mala comparada con la luz de día. El más brillante alumbrado eléctrico estaba lejos de la luz solar; mucho menos, pues, el alumbrado a gas, el de nuestras moradas, la lámpara de la costurera, como la bujía de nuestros abuelos. Desde que la imagen de la retina no era bastante luminosa para dar lugar a una clara visión, la pupila se dilataba, aumentaban todas las imperfecciones ópticas del ojo, y, por consiguiente, el órgano se dilataba. Era menester un alumbrado más amplio. ${ }^{51}$

Los principios que se acababan de exponer, debían servir para una ampliación más rigurosa, cuando se tratara de los niños, cuyo globo ocular era apto a variar de forma alargándose y fijándose de este modo el nacimiento de la miopía a partir de la edad en que los niños comienzan a leer. En una época de la edad en que la lectura exigía una atención más precisa que más tarde y en que los jóvenes estudiantes tenían que luchar contra el mal alumbrado de las clases, conviene mucho evitar todo aquello que les ocasione la miopía. Muchos esfuerzos se han ensayado en estos últimos años con relación al alumbrado en las escuelas.

\footnotetext{
${ }^{51}$ Ibídem., p. 461.
} 
Vicios de la pronunciación. Además de los defectos generales de la lectura, existían vicios particulares de pronunciación. Cecear era pronunciar la $s$ como $z$, y se incurría en tal defecto por mal hábito o por defecto de conformación, permitiendo a la lengua pasar de los dientes cuando se pronunciaba la s. Se decía que el mayor inconveniente de este defecto era que daba aire de imbécil. Por lo tanto, este defecto debía corregirse y el medio para lograrlo era lo más sencillo, pues se reducía al ejercicio continuo y por largo tiempo de pronunciar la $s$, apoyando fuertemente el extremo de la lengua en la parte interior de los diente superiores. Esta gimnasia habituaba la lengua a no salir del recinto fortificado de la dentadura, con lo que se corregía el defecto.

Cuando se pronuncia la $\mathrm{r}$ con la base de la lengua, con la garganta misma, en vez de hacerlo con el extremo resulta una pronunciación impropia y desagradable. Pronunciar bien la $r$ era hacerla vibrar con el fin de lograr una buena pronunciación. Para corregir la mala pronunciación de esta letra se citaba a una experiencia que tuvo un actor de teatro. Hay dos letras que todo el mundo pronuncia siempre y naturalmente con el extremo de la lengua la $t$ y la $d$ pues bien se debía pronunciar alternativamente dichas letras, y después poco a poco, les agregaban la $r$; con el fin de sacarla del fondo de la garganta para que respondiera al llamado de sus dos compañeras. De tal manera que con el tiempo podía vibrar sola sin la presencia de aquellas.

Estos dos defectos de pronunciación les valían a los estudiantes unas buenas semanas de castigo y sanción escolar ${ }^{52}$.

La higiene de la lectura también contribuyó a enseñar a respirar. Aunque parecía un acto natural en el mundo aprender a respirar implicaba leer bien y si no se respiraba bien por ende la lectura era deficiente. Este era uno de los talentos más importantes que debería tener todo niño lector, pues bien cuando se respiraba en la vida ordinaria el aire entraba en los pulmones y salía a manera de corriente continua; este mismo fenómeno ocurría cuando se hablaba o se leía. Se apretaba el aire que contenía los pulmones se lanzaba sobre la garganta y sobre la influencia de este choque se producía la palabra, había que respirar naturalmente sin esfuerzo y se comparaba, en la lectura, como el agua que brotaba al golpe de una bomba. El aire que el niño debería retener en los pulmones tenía que ser suficiente para producir palabras continuas y enérgicas. Así se realizaban dos actos: Aspirar y respirar. Aspirar era almacenar y respirar gastar. Los dos eran artes diferentes.

${ }^{52}$ REVISTA DE LA INSTRUCCIÓN PÚBLICA. (1905). El arte de la lectura primera parte, capítulo 7. Tomo 12. Bogotá, Imprenta Nacional, p. 625. 
Respirar implicaba llenar el pulmón con suficiente provisión para no quedarse en medio de la lectura agotado y cansado. Si tenía que hacer una lectura larga, el lector parecía un viajero que partía a través de un desierto con un jarrón de agua a medio llenar; faltaba el aire y tenía que volver a volver a buscar más, lo cual era fatigoso como para el que leía como para el que escuchaba.

EL primer deber del lector era aspirar profundamente al comienzo de tal manera que abasteciera bien los pulmones. EL segundo acto era el más difícil: gastar el aire de los pulmones. Un mal lector no aspiraba bastante y respiraba demasiado; es decir que consumía su capital sin orden y media; arrojaba el aire por las ventanas como el prodigo arroja su dinero; lo gastaba en superfluidades en vez de distribuirlo con ciencia y con prudencia; en una palabra no sabía desembolsarlo espléndidamente en las grandes ocasiones y manejarlo con prudencia en las pequeñas. El lector y el orador, del mismo modo que ciertos actores y cantantes se veían obligados a recurrir a la bomba a cada momento y dar esos ruidosos y roncos golpes de aspiración que se llamaban hipidos, y el que escuchaba sufría tanto como el que hablaba. ${ }^{53}$

\section{Higiene de la escritura inclinada}

Muchas de las discusiones que se dieron a comienzo del siglo XX en Colombia entorno a la escritura giraron de los inconvenientes que se atribuían a la escritura inclinada o a la letra inglesa. Hablar de letra derecha, es decir perpendicular al renglón en que se escribía era hablar de una novedad muy grande, diferente a los hábitos de ese momento. La costumbre era escribir letra inclinada en todas las escuelas.

Cualquier tipo de escritura tenía dos partes una teórica y una práctica. EL hábito solo se conseguía después de muchos ejercicios realizados por mucho tiempo de tal manera que la letra inclinada requería ensayarse y ejecutarse hasta lograr el hábito adecuado. Desde tomar la pluma hasta realizar a la perfección la letra era un principio del hábito que solo se lograba con la experimentación, este tipo de letra inclinada generaba problemas de espalda y lentitud en la toma de notas y dificultad en la ejecución y en la salud. Se creía que la letra inglesa o inclinada era más bella que la derecha. La letra inclinada demanda más tiempo que la derecha. ${ }^{54}$

\footnotetext{
${ }^{53}$ REVISTA DE LA INSTRUCCIÓN PÚBLICA DE COLOMBIA. (1905). Sección pedagógica el arte de la lectura primera parte. Capitulo IV Tomo XIII. Número 3, p. 449.

${ }^{54}$ REVISTA DE LA INSTRUCCIÓN PÚBLICA DE COLOMBIA. (1896). Sección pedagógica de la escritura derecha Tomo V. Bogotá. Imprenta de la Luz, p. 69.
} 
Algunos experimentos se realizaron en las escuelas con el fin de verificar que tipo de letra era más rápida y elegante. Se sabía que a los niños les enseñaban a escribir bien, tomando el tiempo necesario hasta escribir perfectamente; pero que si a esos niños les pedían que lo hicieran con una mayor velocidad posible harían una letra detestable. Con lo anterior se concluía que era necesario que los niños aprendieran a escribir con celeridad y elegancia era necesario un tipo de letra diferente a la inclinada. Se mencionaba que en Estado Unidos por ejemplo se enseñaba la letra inclinada pero sin gruesos. Haciendo modificaciones en el carácter de la escritura y mediante mucha práctica especial con el fin de escribir rápidamente.

La letra derecha de trazos finos o medianos era la más favorable a la consecución de la rapidez. La letra derecha se había enseñado como letra normal y se enseñaba con más facilidad que la letra inglesa. Los niños desde los primeros momentos empezaban a trazar letras más regulares, más iguales, más paralelas, más hermosas que si empezaran a escribir letra inglesa y era notable el progreso del curso en las escuelas primarias. ${ }^{55}$

Se hizo un ensayo en una escuela en los grados primero, segundo y tercero y se observo como los niños tenían una letra hermosa tanto en lápiz como en tinta, siempre y cuando se les facilitara la elaboración de la letra derecha más que de la letra inclinada. En cuanto a la parte higiénica se observaba la belleza y la rapidez de la escritura. A menudo valía más hacer una letra regular rápidamente, que una letra buena con lentitud; pero en la práctica común de las personas la celeridad valía más o tanto que la hermosura. La prontitud del aprendizaje era otra condición digna de tomarse en cuenta, pero las ventajas higiénicas tenían una importancia que superaba a todas las anteriores.

Los higienistas planteaban que la letra inclinada es decir inglesa o cualquier otra era nociva a la salud. Los médicos y pedagogistas habían encontrado que los niños inclinaban el cuerpo hacia la izquierda; esta posición del cuaderno les obligaba a sentarse de lado para mirar perpendicularmente los renglones. EL niño no tenía el cuaderno así, necesitaba colocarse de esta manera formando ángulo la diestra de su pecho con el borde de la mesa a fin de que la línea de los ojos estuviera paralela a los renglones del cuaderno en que escribía. Esta era una posición que tomaba el niño naturalmente, y que tomando esta posición había tenido que inclinar la cabeza hacia el mismo lado del cuaderno; y entonces el cuerpo tomaba esta misma curvatura al igual que la cabeza, y como consecuencia la desviación de la columna vertebral y elevación desigual de los

\footnotetext{
${ }^{55}$ Ibídem., p.72.
} 
hombros, ocasionados por la continuidad de aquella posición oblicua. Además era necesario inclinar hacia adelante el cuerpo; la cual era una inclinación natural exigida por la posición del cuaderno. Entonces esta parte del cuerpo formaba un pliegue entrante juntamente con los vestidos. El pliegue oprimía el estómago e importantes vasos sanguíneos; junto con la región interior del tórax que era con la que respiraban las niñas y todos los varones.

Se restringían así las funciones digestivas, la respiración, la circulación de la sangre y las funciones capitales del organismo, por consiguiente, mala digestión, alimentación insuficiente; y con el tiempo debilidad, anemia, predisposición a sufrir todo género de enfermedades infecciosas, y peligro de sucumbir por falta de resistencia ${ }^{56}$.

Se ordenó que los maestros corrigieran este defecto de posición manteniendo el cuaderno inclinado hacia la izquierda procurando que los niños se sentaran y miraran de frente pero los esfuerzos fueron inútiles. Se ensayo entonces la escritura inglesa dándole la vuelta al cuaderno hacia la derecha, y haciendo colocar el cuerpo de frente a la mesa. Los niños entonces tomaron una posición oblicua, acercando al borde del pupitre su costado izquierdo, debido a que teniendo que inclinar la letra en la misma dirección del cuaderno no hallaban otro medio de colocar el brazo y tomar la pluma de modo que fuera posible la ejecución de los brazos. La oblicuidad del cuerpo iba acompañada también de esa experiencia de curvatura lateral, de inclinación hacia adelante y de pliegue hacia la región del estómago. Y por lo mismo era causa de la desviación de la columna vertebral y de graves perturbaciones de las funciones que más interesan a la conservación de la vida. ${ }^{57}$

Se notaba que la desviación del espinazo era mayor y más pronunciada en las mujeres porque favorecía el equilibrio del cuerpo poniendo los vestidos como especie de calzo debajo del muslo que no descansaba bien en el asiento posición está más antigénica y perjudicial que la anterior. Finalmente se sugirió realizar la escritura inclinada o inglesa teniendo el cuaderno derecho y obligar también al cuerpo a permanecer derecho; pero que estas posiciones no permitían dar la inclinación que la letra inglesa requería y que los niños con el fin de evitar el esfuerzo del brazo y de la mano se sentaban inclinados.

Así la letra inclinada en cualquier sentido debía ser desechada en absoluto. Se sugería que con la letra derecha los niños se sentaban espontáneamente con la posición normal frente a la mesa con el cuerpo vertical la cabeza algo inclinada

${ }^{56}$ Ibídem., p. 74.
${ }^{57}$ Ibídem, p. 74. 
hacia adelante, descansando los dos antebrazos igualmente sobre la mesa, los dos hombros a igual altura que permitían escribir con mucha soltura y así se sabía que la letra derecha era un tipo de letra higiénica. ${ }^{58}$

\section{Higiene de la escritura derecha}

Los higienistas y pedagogos europeos y americanos, en sus respectivas esferas, trataron el tema de la escritura, como un tema importante en las escuelas. La estudiaban atenta y profundamente con el fin de concluir qué tipo de escritura era la más recomendable desde el punto de vista de la higiene y la pedagogía. Para algunos la conclusión fue que la escritura recta o vertical se ajustaba mejor a las condiciones de higiene que requería el cuerpo y por lo tanto la pedagogía debía promoverla y llevarla a feliz término con los alumnos.

Así se daban ejemplos de los experimentos que se realizaban para combatir la miopía y donde los progresos eran evidentes ${ }^{59}$. Se proponía utilizar la formula siguiente: escritura recta, papel recto y cuerpo recto. Así se esperaba corregir las enfermedades del cuerpo como la esclerosis y la miopía. De igual manera, se manifestaba que los niños tenían una tendencia natural a escribir recto; y que para comprobar esto había que ver a los niños principiantes como lo hacían.

\section{Los beneficios del canto en las escuelas}

Se tomaba como una de las grandes conquistas de la pedagogía moderna, la enseñanza de los cantos corales en las escuelas. Estos eran considerados indispensables en toda la escuela, la cual estaba organizada de conformidad con los principios de la nueva ciencia de educar.

Se establecía que cantar promovía la expresión oral y por ende un mejor desempeño en la lectura. Así mismo se recomendaba formar mejores ciudadanos capaces de interrelacionarse entre sí, por medio de la música y el canto. Se distribuyeron las horas en cada año escolar elemental y se promovió en cada evento que realizara la escuela. ${ }^{60}$

\section{La miopía en las escuelas. Reglas higiénicas para evitarla}

Un tema que preocupaba a los líderes de la educación del país era mejorar

\footnotetext{
${ }^{58}$ Ibídem, p. 77.

${ }^{59}$ REVISTA DE LA INSTRUCCIÓN PÚBLICA DE COLOMBIA. (1898). Tomo VIII.

Bogotá, Tipografía de la luz, p. 75.

${ }^{60}$ Ibídem., p. 403.
} 
las condiciones físicas de los estudiantes y evitar las malas condiciones higiénicas sociales en las que se encontraba el país en el momento.

La miopía fue estudiada con el fin de encontrar las causas que la originaban entre los alumnos de las escuelas y los colegios, junto con los medios para evitarla. Se planteaba que la causa principal de las perturbaciones oculares que traían consigo la miopía, se debía a los trabajos escolares, a su duración y la distancia excesivamente corta a la cual estos trabajos se efectuaban; que si no se tomaban en consideración estas ideas fundamentales, serían muy poco útiles y poco provechosas las mejoras en reglas higiénicas, las cuales se prescribían como auxiliares para una buena lectura y escritura. ${ }^{61}$ Así se sugería que las clases no debían suceder unas inmediatamente de las otras, la duración no debían exceder tres cuartos de hora, dejando intervalos de quince minutos entre una y otra. En este tiempo se ventilaban los salones y se dejaban así descansar los ojos el tiempo necesario para el reposo. De aquí surgía la necesidad de que el niño reposara de sus trabajos escolares los días domingos y fiesta.

Así mismo, se sugería que los salones debían ser espaciosos, ventilados y recibir una luz proporcionalmente considerable. De ahí la necesidad de que estos estuvieran completamente aislados. Se aceptaba como suficiente para obtener la luz necesaria que un salón de cinco metros cuadrados de superficie tuviera un metro de ventana de vidrio. La luz no debería ser reflejada por cuanto producía contracciones espasmódicas de la acomodación. La luz del sol no podía penetrar directamente en los salones. ${ }^{62}$

En cuanto al mobiliario de la escuela, la parte que se refería a los asientos y a las bancas destinadas a la escritura, tenía una importancia considerable, si se querían evitar las deformaciones laterales de la columna vertebral y la inclinación de la cabeza , como unas de las causas poderosas para favorecer frecuentemente el desarrollo de la miopía. No eran los niños quienes debían adaptarse a las bancas sino las bancas debían hacerse para ellos. Se establecían cuatro tipos de bancas para los establecimientos escolares en general, en relación con la edad y tamaño de los alumnos que frecuentaban las escuelas. Se preferían las bancas de un solo puesto. Se aclaraba que al superficie de la mesa debía guardar una relación determinada de distancia con el asiento más o menos un octavo del cuerpo, para que los tracanteres guardaran proporción con relación a los codos, conservando así los ojos una distancia conveniente respecto de la mesa de escribir, para procurar de esta manera que el antebrazo y la mano no

${ }^{61}$ REVISTA DE INSTRUCCIÓN PÚBLICA. Tomo V. óp., cit, p. 121.

${ }^{62}$ Ibídem., p. 122.

Rev. hist. edu. latinoam. Vol. 15. Año 2010, pp. 271 - 298 
hiciera un gran movimiento de elevación, impidiendo el excesivo levantamiento de los hombros, lo que impedía seguramente una colocación viciosa de la columna vertebral. ${ }^{63}$ Pero a pesar de estas indicaciones se sabía que los alumnos no se sentaban convenientemente, inclinaban la cabeza y la hacían girar sobre el tronco, razón por la cual se recurría al empleo de aparatos especiales para impedir este mal hábito. Los niños se sentaban mal para escribir y mucho peor para leer, y se ha probado que esta mala colocación de la cabeza tiene gran influencia en el desarrollo de la miopía.

Así mismo, se aclaraba la colocación del papel para la escritura; las letras y las líneas debían conservar una dirección determinada y colocarse bajo un ángulo bien preciso, pues de esta manera se daba una inclinación anormal a la cabeza y la parte superior del cuerpo. Multitud de observaciones y sugerencias se hicieron alrededor de la idea de higiene de la lectura y la escritura, lo mismo que se establecieron las ventajas higiénicas de los diversos métodos de enseñanza de la lectura y la escritura.

Alguno métodos se consideraron perjudiciales especialmente, aquellos que empleaban un complicado sistema de líneas o un considerable número de puntos, o bien aquellos donde había un considerable número de puntos o bien a aquellos donde había una gran cantidad de figuras de líneas finas o de puntos, prefiriendo aquellos donde las líneas eran de mayor tamaño y estaban separadas por una distancia mayor.

\section{CONCLUSIONES}

Si bien la escuela primaria a finales del siglo XIX y comienzos del XX, afrontó problemas pedagógicos de enseñar a leer y escribir, bajo condiciones de precariedad económica, social y de salubridad pública; se puede concluir que fueron las condiciones físicas, climatológica y de salud pública, las que imperaron sobre los procesos de alfabetización de las culturas aborígenes y mestizas del país. La preocupación por los problemas higiénicos en las clases menos favorecidas y la idea de mejorar la raza trajo consigo el reconocimiento de otro ideal, que se esperaba alcanzar por medio de la instrucción y la alfabetización, sin embargo, ajenos a encontrar soluciones a las necesidades escolares que se presentaban, se buscó borrar lo autóctono y originario de los niños, porque implicaba decadencia y degeneramiento, para promover lo ajeno y extranjero.

\footnotetext{
${ }^{63}$ Ibídem., p. 123.
} 
Doris Lilia Torres - Tulio Alfonso Ramírez

De acuerdo con la Constitución de 1886, la firma del Concordato con el Vaticano en 1887, la implementación del Syllabus de Pio IX y de Rerum Novarum de León XIII, el Ministerio de Instrucción y Salubridad Pública de Colombia dejo en manos de las Misiones Católica la educación del país y la catequización de las comunidades educativas. Ellos cumplieron su misión fieles a sus preceptos cristianos y, se puede decir, salvaron e instruyeron en la fe a muchos de nuestros pueblos mestizos e indígenas, heredándonos el desprecio por lo propio, por lo autóctono, lo cultural e impidiéndonos ver a través de la lectura y escritura explorar el entorno, descubrir lo que somos y reconocernos con la suficiente autoestima por lo que nos rodea en medio de la diversidad y multiculturalidad.

La Guerra de los Mil Días, le aportó a la educación la destrucción y devastación de los locales y muebles escolares. Nunca se sabrá con certeza la pobreza y la ruina que dejo esta guerra y mucho menos se llegará a conocer el estado en que quedaron las escuelas, pero lo único cierto es que hoy en día, después de cien años, y con base en las estadísticas de alfabetización, Colombia es un país no lector.

\section{FUENTES}

ACUERDO NÚMERO 6 DE 18 DICIEMBRE DE 1905

DIARIO OFICIAL 20307 lunes 27 de septiembre de 1926.

EL TERCER CONGRESO MÉDICO COLOMBIANO, Cartagena en enero de 1918.

INFORME DEL VICARIO APOSTÓLICODE CASANARE. (1905): Inspector de Instrucción Pública en las Escuelas de Este territorio de la Intendencia del Meta.

INFORME DE DIRECTOR DE INSTRUCCIÓN PÚBLICA DEL DEPARTAMENTO DE CUNDINAMARCA. (1905): Bogotá, Imprenta Nacional, Julio 31 de. Número 1.

JIMÉNEZ, M. La locura en Colombia y sus causas, en: Revista Cultura. Vol. 3, Nro. 16.

JIMÉNEZ, M. (1920): Nuestras razas decaen. Algunos signos de degeneración colectiva en Colombia y en los países similares. El deber actual de la ciencia. Bogotá, Imprenta y litografía de Juan Casis.

LEY 1926 0012. (Septiembre 25). "Sobre enseñanza de la higiene, saneamiento de los puertos marítimos, fluviales y terrestres y de las principales ciudades de la República”

REVISTA DE LA INSTRUCCIÓN PÚBLICA DE COLOMBIA. Periódico Oficial destinado al fomento y a la estadística de los establecimientos de la enseñanza pública, Bogotá, Imprenta Nacional.

REVISTA DE LA INSTRUCCIÓN PÚBLICA DE COLOMBIA (1893). Sección Científica. La Higiene de las escuelas. Tomo I. Bogotá, Tipografía de la luz. 
REVISTA DE LA INSTRUCCIÓN PÚBLICA DE COLOMBIA. (1896). Sección pedagógica de la escritura derecha Tomo V. Bogotá, Imprenta de la Luz.

REVISTA DE LA INSTRUCCIÓN PÚBLICA DE COLOMBIA. (1898). Tomo VIII. Bogotá, Imprenta de la Luz.

REVISTA DE LA INSTRUCCIÓN PÚBLICA DE COLOMBIA. (1898). Tomo VIII. Bogotá, Tipografía de la luz.

REVISTA DE LA INSTRUCCIÓN PÚBLICA DE COLOMBIA. (1905). Enseñanza antialcólica. Bogotá, Imprenta Nacional.

REVISTA DE LA INSTRUCCIÓN PÚBLICA DE COLOMBIA. (1905): Las mejoras sanitarias. Tomo XVIII. Número 2. Bogotá, Imprenta Nacional.

REVISTADE LAINSTRUCCIÓN PÚBLICADE COLOMBIA(1905). Juntas Centrales de Higiene. Tomo XVII- Julio a Diciembre. Bogotá, Imprenta Nacional.

REVISTADE LA INSTRUCCIÓN PÚBLICA DE COLOMBIA. Sección científica. Tomo I. Bogotá, Tipografía de la luz.

REVISTA DE LA INSTRUCCIÓN PÚBLICA. (1905). El arte de la lectura primera parte, capítulo 7. Tomo 12. Bogotá, Tipografía de la luz.

REVISTADE LAINSTRUCCIÓN PÚBLICA DE COLOMBIA. (1905). Sección pedagógica el arte de la lectura primera parte. Capitulo IV Tomo XIII. Número 3. Bogotá, Imprenta de la Luz.

RINCÓN, Carlos. (2007): Seminario Universidad y nación. Doctorado en Ciencias de la EducaciónRUDECOLOMBIA. Tunja, Boyacá, Colombia. Cátedra de 13 de Noviembre de 2007.

VALLE ATILES, F. (1893): “La higiene de la inteligencia," en: Revista de la Instrucción Pública de Colombia. Tomo I. Bogotá, Imprenta de la luz.

\section{REFERENCIAS}

ORTIZ, Fernando. (1966): "las Razas y los Negros". Gustavo J. Godoy Journal of Inter-American Studies, Vol. 8, No. 2 .Published by: Center for Latin American Studies at the University of Miami .Stable URL: http://www.jstor.org/stable/165106.

VASCONCELOS, José. (1926): La raza cósmica. Misión de la raza iberoamericana. Notas de viaje a la América del Sur. Barcelona, Agencia Mundial de Librería.

MCGRAW, Jason. (2001): Purificar la nación: eugenesia, higiene y renovación moral-racial de la periferia del Caribe colombiano, 1900-1930. rev.estud.soc. [online]. n.27.

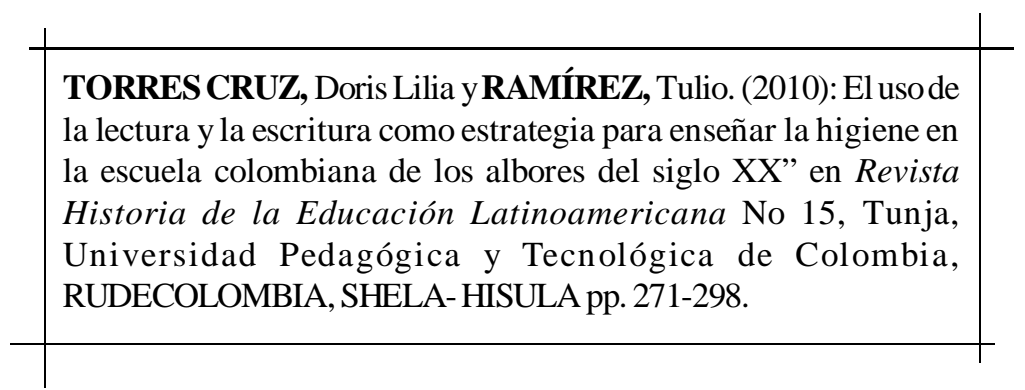

Rev. hist. edu. latinoam. Vol. 15. Año 2010, pp. 271 - 298 